\title{
A new stoichiometric miniaturization strategy for screening of industrial microbial strains: application to cellulase hyper-producing Trichoderma reesei strains
}

Etienne Jourdier ${ }^{1}$, Laurent Poughon ${ }^{2}$, Christian Larroche ${ }^{2}$, Frédéric Monot ${ }^{1}$ and Fadhel Ben Chaabane ${ }^{1 *}$

\begin{abstract}
Background: During bioprocess development, secondary screening is a key step at the boundary between laboratory and industrial conditions. To ensure an effective high-throughput screening, miniaturized laboratory conditions must mimic industrial conditions, especially for oxygen transfer, feeding capacity and pH stabilization.

Results: A feeding strategy has been applied to develop a simple screening procedure, in which a stoichiometric study is combined with a standard miniaturization procedure. Actually, the knowledge of all nutriments and base or acid requirements leads to a great simplification of $\mathrm{pH}$ stabilization issue of miniaturized fed-batch cultures. Applied to cellulase production by Trichoderma reesei, this strategy resulted in a stoichiometric mixed feed of carbon and nitrogen sources. While keeping the $\mathrm{pH}$ between shake flask and stirred bioreactor comparable, the developed shake flask protocol reproduced the strain behaviour under stirred bioreactor conditions. Compared to a an already existing miniaturized shake flasks protocol, the cellulase concentration was increased 5 -fold, reaching about $10 \mathrm{~g} \mathrm{~L}^{-1}$. Applied to the secondary screening of several clones, the newly developed protocol succeeded in selecting a clone with a high industrial potential.

Conclusions: The understanding of a bioprocess stoichiometry contributed to define a simpler and more effective miniaturization. The suggested strategy can potentially be applied to other fed-batch processes, for the screening of either strain collections or experimental conditions.
\end{abstract}

Keywords: Screening, Miniaturization, Stoichiometry, Fed-batch, pH Control, Cellulase, Trichoderma reesei

\section{Background}

Bioprocess development and miniaturization

During the development of an industrial process involving micro-organisms, the screening of strain collections is a compulsory step for the selection of a strain exhibiting the best performances in industrial conditions. The screened collections can be issued from any primary screening and they often contain hundreds of strains which economically cannot all be tested at a large scale. Therefore, the secondary screening step must be carried out at a small scale, but representative of industrial

\footnotetext{
* Correspondence: fadhel.ben-chaabane@ifpen.fr

${ }^{1}$ IFP Energies nouvelles, 1 et 4 avenue de Bois-Préau, 92852 Rueil-Malmaison, France

Full list of author information is available at the end of the article
}

conditions. Any minor difference between screening method and large scale cultivation protocol may lead to the selection of a clone which is inappropriate for an industrial process [1].

Current bioprocess development steps are presented in Figure 1. Strain construction is carried out on agar-based solid medium supplemented with a specific substance chosen for the screening (e.g. the substrate of the biotransformation, or a resistance marker). Then screenings are performed in liquid cultures, generally in shake flasks, but many methods have been developed to miniaturize and automate this step. Direct miniaturization of shake flasks to around $1 \mathrm{~mL}$ can be carried out in microtiter plates (MTPs) and several high-throughput devices are commercially available for automated monitoring of

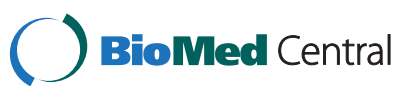




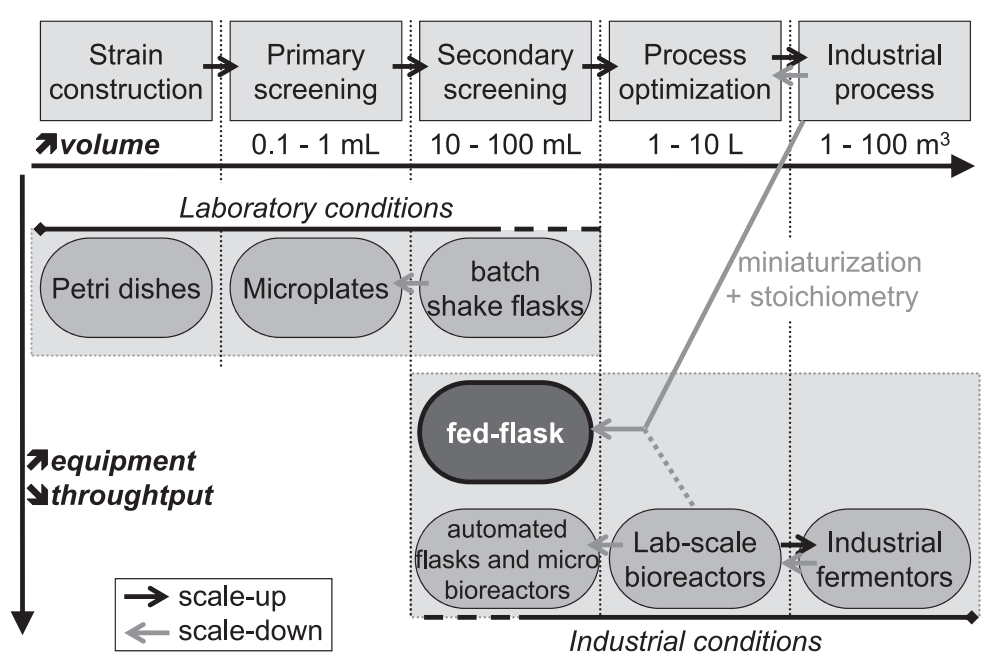

Figure 1 Bioprocess development steps and available methods for each step. Unlike batch operated shake flasks, the fed-flask protocol described here allows industrial-like operating conditions but with less equipment than microbioreactors or automated shake flasks.

growth, oxygen partial pressure and $\mathrm{pH}$ by optical sensors [2]. For a better control of the operating conditions (mainly $\mathrm{pH}$ and dissolved oxygen), microbioreactors have been developed by miniaturization of the laboratory scale bioreactor, with two distinct strategies. On the one hand, microfluidic chips have been designed to equip MTPs with micropumps for $\mathrm{pH}$ control and substrate feed [3]. On the other hand, stirred tank or bubble column reactors have been miniaturized down to 10 and $2 \mathrm{~mL}$ respectively $[4,5]$, but these low volumes may be critical for off-line analysis.

Microbioreactors have been developed for a wide range of applications, with a material-based approach, in order to precisely mimic lab-scale bioreactors. They may be applied for high-throughput screening thanks to their low volumes but they are quite complex to handle and their operating conditions may be a limiting issue. For example, the optical sensors used for $\mathrm{pH}$ monitoring in microbioreactors are not useable below pH 5.5 [6], and feeding is seldom possible whereas industrial processes are frequently operated in fed-batch mode.

Recently, two simple techniques have been proposed to handle glucose-limited fed-batch in shake flask: the slow release of glucose crystals from silicon elastomer discs [7], and the enzymatic glucose release from polysaccharides $[8,9]$. The first one can also be used with $\mathrm{Na}_{2} \mathrm{CO}_{3}$ crystals for $\mathrm{pH}$ stabilization [10]. However, in both cases, the feed rate, although reproducible, cannot be set and controlled so that these techniques are suitable only for a primary screening. For precise fed-batch operation in shake flasks with minimum equipment, Weuster-Botz et al. proposed a parallel substrate feeding strategy in which a single pump is used to feed successively up to 16 shake flasks [11]. For $\mathrm{pH}$ control, a second pump can be used in the same way for base feed. However, in this case, this system requires one $\mathrm{pH}$ probe and two feed lines for each flask.

Bareither and Pollard [12] recently reviewed smallscale bioreactors available on the market or in development and concluded that no single device has yet succeeded in a miniaturization which retains full functionality of conventional bioreactors. Therefore the choice or design of a miniaturized device must be based on the main characteristics of the planned industrial process.

\section{Cellulase production using Trichoderma reesei}

The study case chosen for the test and validation of this strategy is cellulolytic enzymes (cellulases) production using recombinant $T$. reesei strains. $T$. reesei is a fungus with very high protein secretion capacity which has been successfully cultivated at industrial scale for cellulase production [13]. Novel industrial T. reesei strains are the result of genetic improvement programmes often including high-throughput screening steps [14].

Cellulase production by $T$. reesei requires an inducer of the cellulolytic system. The natural inducer cellulose, whether pure or in lignocellulosic material, leads to good productions but is hard to handle at an industrial scale because of its insolubility [15]. As a substitute, the disaccharide lactose is the most classic soluble inducer and carbon source [16]. However, even in derepressed strains, cellulase production is very low in the presence of readily-metabolized sugars in excess, which is the case in batch culture [17]. Therefore, soluble inducing carbon sources must be fed continuously, in a fed-batch or continuous protocol, so that their residual concentrations in the bioreactor will remain close to zero. 
The industrial production protocol developed by IFP Energies nouvelles is based on these observations [15]. First, cellular growth is carried out in a batch mode on soluble sugar. Then, when residual sugars concentration comes to zero, cellulase production is carried out in carbon-limited fed-batch mode with concentrated lactose solution, resulting in maximized cellulase production rate. The specific substrate feed rate (equal to the specific substrate uptake rate) is the main criterion for maximized production, and it must be kept constant during scale-up or scale-down approaches. In the industrial stirred bioreactor process, temperature and dissolved oxygen are controlled, and an ammonia solution is used for $\mathrm{pH}$ control at 4.8 and for nitrogen supply. This protocol is too complex to be used for highthroughput screenings.

$\mathrm{pH}$ stabilization is a major criterion for the development of $T$. reesei small-scale cultivation protocols. It should preferably be kept between 4.0 et 5.5, like in industrial protocol. $\mathrm{pH}$ outside this range will stop metabolism and may durably denature produced cellulases, whose optimal $\mathrm{pH}$ is around 5.0. In batch shake flask cultivations without buffer, $\mathrm{pH}$ quickly drops below 3.5 so that many buffer systems have been tested [18,19]. The conclusion varies between authors since the chosen criterion (final enzymatic activity) depends on many factors in batch cultivations.

For the selection of a strain with high industrial potential, one of the most important criterion is the expected protein productivity so that the secondary screening must not be based solely on cellular growth. Since around $90 \%$ of the enzymatic cocktail secreted by $T$. reesei strains in industrial conditions are cellulases [20], the enzymatic activity of a supernatant is proportional to the protein concentration, and protein productivity is closely related to cellulolytic activity productivity. Thus, to free from producing cell biomass, the chosen criterion for the selection of an industrial strain is the specific protein production rate $\mathrm{q}_{\mathrm{P}}$ ( $\mathrm{mg}$ of protein per $\mathrm{g}$ of biomass per hour). For hyper-producing $T$. reesei strains, its value is below $5 \mathrm{mg}_{\mathrm{P}} \mathrm{g}_{\mathrm{X}}^{-1} \mathrm{~h}^{-1}$ in batch cultivation whereas it reaches around $15 \mathrm{mg}_{\mathrm{P}} \mathrm{g}_{\mathrm{X}}^{-1} \mathrm{~h}^{-1}$ in carbon-limited fed-batch or continuous cultivations [17]. Obviously a small-scale cultivation protocol suited for the selection of industrial strains has to allow high specific protein production rate, which requires fed-batch mode.

Recently, Cianchetta et al. described a screening strategy consistent with cultivations in batch shake flasks for the identification of hypercellulolytic $T$. reesei strains [21]. However in their shake flask protocol, the strains were cultivated with excess cellulose so the results cannot be extrapolated to the industrial carbon-limited protocol. To increase enzyme production in shake flasks, a resting cell strategy is often used, in which a lactose pulse is performed after glucose depletion, but lactose is still in excess [22]. This protocol is thereafter named shake flask pulse protocol. To our knowledge, no smallscale fed-batch protocol has been proposed for the selection of $T$. reesei strains with high industrial potential.

In this study, a stoichiometric miniaturization strategy is described for the design of a simple screening procedure which retains the experimental conditions of an industrial process. This strategy was applied to cellulase production by $T$. reesei which requires carbon-limited fed-batch and $\mathrm{pH}$ stabilization. For fed-batch mode, a standard miniaturization strategy was used. In parallel, a stoichiometric study of the micro-organism behaviour in industrial conditions was performed in order to develop

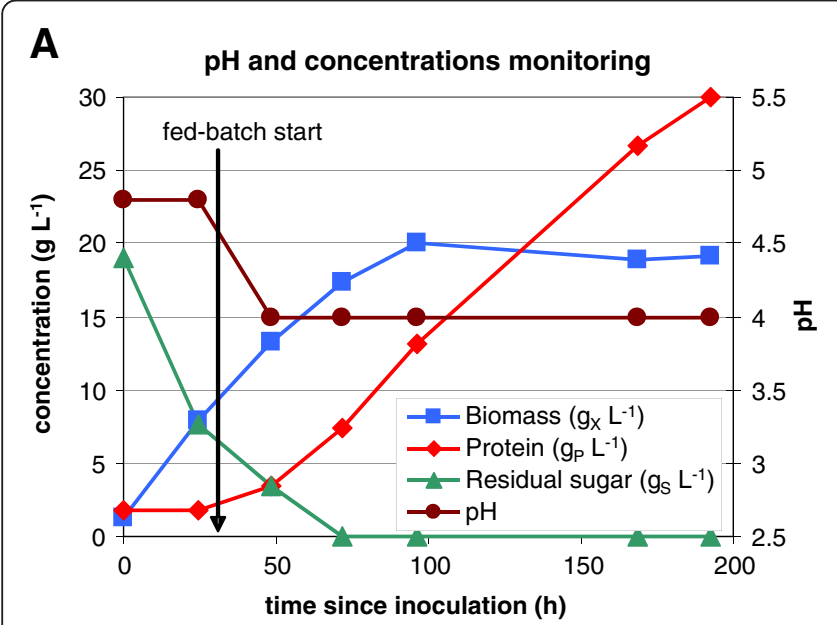

B

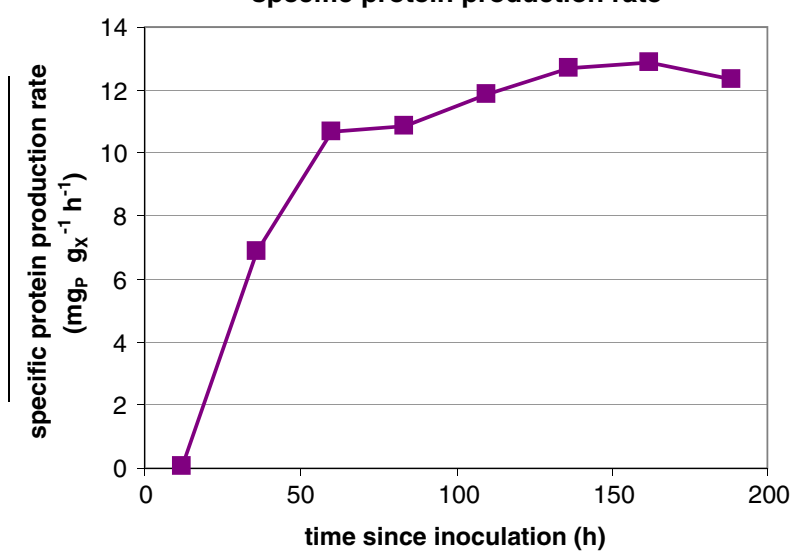

Figure 2 Reference production in bioreactor. Reference strain T. reesei CL847 i $\beta$ was cultivated in $750 \mathrm{~mL}$ bioractor following industrial protocol: batch growth phase on $20 \mathrm{~g} \mathrm{~L}^{-1}$ glucose for $30 \mathrm{~h}$ then fed-batch with $250 \mathrm{~g} \mathrm{~L}^{-1}$ lactose solution at $2 \mathrm{~mL} \mathrm{~h}{ }^{-1}$. (A) pH and concentrations monitoring: cell biomass concentration (blue squares), protein concentration (red diamonds), residual sugar concentration (green triangles) and $\mathrm{pH}$ (brown circles). (B) Specific protein production rate (purple squares). 
a simple $\mathrm{pH}$ stabilization strategy. Usually stoichiometry is used to calculate yield or mass balance. In this work it was used for calculation of nutriments requirement for later medium design. Actually, acid or base requirements for $\mathrm{pH}$ control are stoichiometrically related to nutriments uptake from the culture medium. Accordingly, knowing nutriments needs allows predicting acid or base needs. In practice, no $\mathrm{pH}$ probe is required and base or acid are mixed with the feed, which halves the number of pumps. The resulting protocol (thereafter named "fedflask" mode for stoichiometric fed-batch mode operated in shake flask) was first validated by comparison with reference production in bioreactor and then applied for the secondary screening of various $T$. reesei clones.

\section{Results}

\section{Reference fed-batch production in bioreactor}

The industrial protocol already mentioned [15] was used to perform a reference fed-batch cultivation of $T$. reesei CL847 i $\beta$ strain in lab-scale bioreactor. Monitoring of $\mathrm{pH}$, substrate and products concentrations (Figure $2 \mathrm{~A}$ ), and calculation of the specific protein production rate $\mathrm{q}_{\mathrm{P}}$ (Figure 2 B) showed 3 different phases. During the first 30 hours, cell growth occurred in a batch phase on glucose as a carbon source. Due to the repressor effect of glucose, no protein production was observed during this phase $\left(q_{P}=0 \mathrm{mg}_{\mathrm{P}} \mathrm{g}_{\mathrm{X}}^{-1} \mathrm{~h}^{-1}\right)$. Then, from 30 to 72 hours, the lactose feed induced protein production, but the residual sugar concentration was not null, resulting in a limited induction of the production $\left(\mathrm{q}_{\mathrm{P}}=7 \mathrm{mg}_{\mathrm{P}} \mathrm{g}_{\mathrm{X}}^{-1} \mathrm{~h}^{-1}\right)$. Both biomass and protein were produced. Then, after 72 hours, residual sugars concentration was null, resulting in a high induction of the protein synthesis $\left(\mathrm{q}_{\mathrm{p}}=12.5 \pm\right.$ $0.5 \mathrm{mg}_{\mathrm{P}} \mathrm{g}_{\mathrm{X}}^{-1} \mathrm{~h}^{-1}$ ). Biomass growth stopped and protein production was maximum. During this phase, a protein production yield of $0.36 \pm 0.03 \mathrm{~g} \mathrm{~g}^{-1}$ on lactose was obtained. Final protein concentration after $192 \mathrm{~h}$ total cultivation was $30 \mathrm{~g} \mathrm{~L}^{-1}$.

\section{Stoichiometry of cellulase production}

To understand the nutriments needs during protein production by $T$. reesei, compositional analysis of different secretomes was performed. Measurements were done on 3 desalted secretomes produced by CL847 i $\beta$ strain in 3 independent bioreactor cultivations with lactose feed (same conditions than reference fed-batch production, duration 265, 340 and $240 \mathrm{~h}$, final concentrations 43, 65 and $33 \mathrm{~g} \mathrm{~L}^{-1}$ ). These measurements were compared to the theoretical protein composition based on nucleotidic sequences of the genes coding for the four major cellulases $\mathrm{CBH} 1, \mathrm{CBH} 2$, EG1, EG2 [23], which account for around 75\% of the secretome [20]. Results showed large differences between theoretical and measured compositions (Table 1). Whereas carbon and hydrogen content were quite equivalent, oxygen
Table 1 Theoretical and measured compositions of T. reesei secretome

\begin{tabular}{ccll}
\hline & theoretical & \multicolumn{2}{c}{ measured } \\
\cline { 3 - 4 } & mass content & mass content & molar composition \\
\hline $\mathbf{C}$ & $53.0 \pm 0.9 \%$ & $47.3 \pm 0.1 \%$ & 1 \\
H & $6.6 \pm 0.1 \%$ & $6.83 \pm 0.04 \%$ & 1.733 \\
$\mathbf{O}$ & $23.2 \pm 0.7 \%$ & $32.0 \pm 0.8 \%$ & 0.508 \\
$\mathbf{N}$ & $16.7 \pm 0.2 \%$ & $12.7 \pm 0.5 \%$ & 0.23 \\
$\mathbf{S}$ & $1.6 \pm 0.5 \%$ & $1.00 \pm 0.05 \%$ & 0.008 \\
Total & $100.1 \pm 2.4 \%$ & $99.7 \pm 0.6 \%$ & \\
\hline
\end{tabular}

Three independent final secretomes produced by $T$. reesei CL847 i $\beta$ under reference fed-batch production in bioreactor (with lactose feed) were desalted and analysed for their elementary compositions (values are mean and standard deviation of the 3 secretomes). Theoretical composition was based on amino-acids sequences of the fourth main cellulases.

content was $38 \%$ higher and nitrogen and sulfur content were $24 \%$ and $38 \%$ lower, respectively, in the measured composition compared to the theoretical one. Using mean measured secretome composition and measured production yield, the overall stoichiometry of protein production by $T$. reesei on lactose when no residual sugars (no biomass growth) was determined as:

$$
\begin{gathered}
\mathrm{CH}_{1.833} \mathrm{O}_{0.917}+0.597 \mathrm{O}_{2}+0.093 \mathrm{NH}_{3} \downarrow 0.400 \mathrm{CH}_{1.733} \\
\mathrm{O}_{0.508} \mathrm{~N}_{0.23}+0.600 \mathrm{CO}_{2}+0.708 \mathrm{H}_{2} \mathrm{O}
\end{gathered}
$$

During protein production on lactose, no other metabolite such as an organic acid is consumed or produced, so this equation describes all the biological reactions occurring during protein production. For instance, using this equation, the calculated carbon balance for the third phase of the reference bioreactor production (After $72 \mathrm{~h}$ : protein production with no growth) was $0.95 \mathrm{gC}_{\text {produced }}$ $\mathrm{gC}_{\text {consumed }}^{-1}$, which proves that every carbon substrate and product were considered.

\section{Fed-flask protocol design}

For the design of the new fed-flask protocol, a standard miniaturization of the lab-scale bioreactor was first carried out at constant specific substrate feed rate (Table 2). Flasks were chosen for their simplicity to handle and rotary shaker for easy agitation and temperature control. After preliminary experiments, working volume $(50 \mathrm{~mL})$ and biomass concentration (7 to $\left.8 \mathrm{~g} \mathrm{~L}^{-1}\right)$ were chosen to avoid oxygen transfer limitation (see Discussion). Initial glucose concentration for batch phase $\left(15 \mathrm{~g} \mathrm{~L}^{-1}\right)$ was chosen to reach the biomass concentration. Temperature was not a critical issue since the optimal range for $T$. reesei is wide [15]. Feed rate and lactose concentration in feed were chosen to keep constant the specific substrate feed rate.

Then, a stoichiometric approach was used to remove $\mathrm{pH}$ control system by mixing the base with the substrate feed (Table 2 and Figure 3). With this strategy, no $\mathrm{pH}$ 
Table 2 Conditions used for the stoichiometric miniaturization strategy

\begin{tabular}{|c|c|c|c|c|}
\hline & & bioreactor protocol & fed-flask protocol & miniaturization fold \\
\hline \multicolumn{2}{|c|}{ Working volume $(\mathrm{mL})$} & 750 & 50 & $/ 15$ \\
\hline \multicolumn{2}{|c|}{ Biomass concentration $\left(g \mathrm{~L}^{-1}\right)$} & 17 & 7.5 & $/ 2.2$ \\
\hline \multirow[t]{2}{*}{ Feed composition } & lactose $\left(\mathrm{g} \mathrm{L}^{-1}\right)$ & 250 & 50 & 15 \\
\hline & $\mathrm{NH}_{3}(\mathrm{mM})$ & $\left(\right.$ separate $\left.^{1}\right)$ & 160 & \\
\hline \multicolumn{2}{|l|}{ Feed rate $\left(m L h^{-1}\right)$} & 2 & 0.3 & 16.6 \\
\hline \multicolumn{2}{|c|}{ specific lactose feed rate $\left(\mathrm{g} \mathrm{g}^{-1} \mathrm{~h}^{-1}\right)$} & 0.04 & 0.04 & constant \\
\hline
\end{tabular}

probe was required and the number of pumps was halved. The measured stoichiometry of protein production on lactose was used to predict the $\mathrm{NH}_{3}$ base need during fed-batch: $3.2 \mathrm{mmol}$ of $\mathrm{NH}_{3}$ per gram of lactose. Using $50 \mathrm{~g} \mathrm{~L}^{-1}$ lactose feed, $15 \mathrm{~mL}$ of $11 \mathrm{~N}$ ammonia solution were mixed per liter of lactose feed. With the same reasoning, sulfur requirement was calculated to be $0.8 \mathrm{~g} \mathrm{~L}^{-1}$ ammonium sulfate.

\section{Validation of the fed-flask protocol}

Using the reference strain $T$. reesei CL847 i $\beta$, the new fed-flask protocol was compared to the shake flask pulse protocol and to the reference fed-batch production protocol in bioreactor (previously presented Figure 2). For flasks experiments, growth phase was identical, then production was induced with a pulse of $20 \mathrm{~g} \mathrm{~L}^{-1}$ lactose (shake flask pulse protocol) or with a stoichiometric mixed feed of lactose and ammonia (new fed-flask protocol). Off-line monitoring of $\mathrm{pH}$ and concentrations, and calculation of specific protein production rate are presented in Figure 4.

During growth phase on glucose, $\mathrm{pH}$ felt because of ammonium consumption (Figure $4 \mathrm{~A}$ ). This fall was weaker when the culture medium contained $50 \mathrm{mM}$ phtalate than $25 \mathrm{mM}$ owing to the buffer effect of phtalate. However, in shake flask pulse protocol, even 50 $\mathrm{mM}$ phtalate buffer was insufficient to stabilize $\mathrm{pH}$ after the lactose pulse. $\mathrm{pH}$ dropped below 3.3 after $142 \mathrm{~h}$ and biological activity stopped due to low $\mathrm{pH}$ effect. With the new fed-flask protocol, $\mathrm{pH}$ remained constant at 5.0 in $50 \mathrm{mM}$ buffered flask and slightly rose from 4.1 to 4.8 in $25 \mathrm{mM}$ buffered flasks. The use of a feed mixing lactose and ammonia in stoichiometric proportion mimicked the $\mathrm{pH}$ control strategy used for reference fedbatch production in bioreactor and allowed a good $\mathrm{pH}$ stabilization in flasks for more than $150 \mathrm{~h}$.

Biomass and protein concentration profiles were similar in the new fed-flask protocol and in the reference fed-batch bioreactor cultivation (Figure 4 B and C, compared to Figure $2 \mathrm{~A}$ ). After feed start, biomass remained constant (in mass) and protein production was almost linear, reaching $10 \mathrm{~g} \mathrm{~L}^{-1}$ after $160 \mathrm{~h}$ of feeding. No effect of buffer concentration or $\mathrm{pH}$ was observed on the protein production rate. With the shake flask pulse protocol with lactose pulse, protein production rate was 3.5 times lower, and stopped $110 \mathrm{~h}$ after the pulse at $2.3 \mathrm{~g} \mathrm{~L}^{-1}$ due

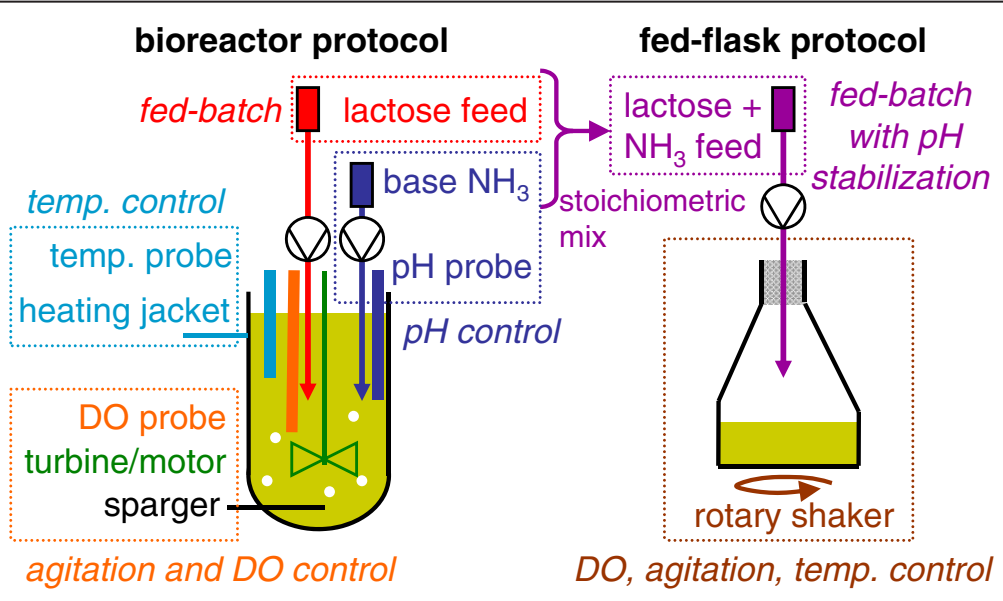

Figure 3 Stoichiometric miniaturization strategy: principle diagram. To reduce needed equipment, substrate feed and base ammonia were stoichiometrically mixed in a single solution. This allows $\mathrm{pH}$ stabilization with halved pump number and no pH probe. 

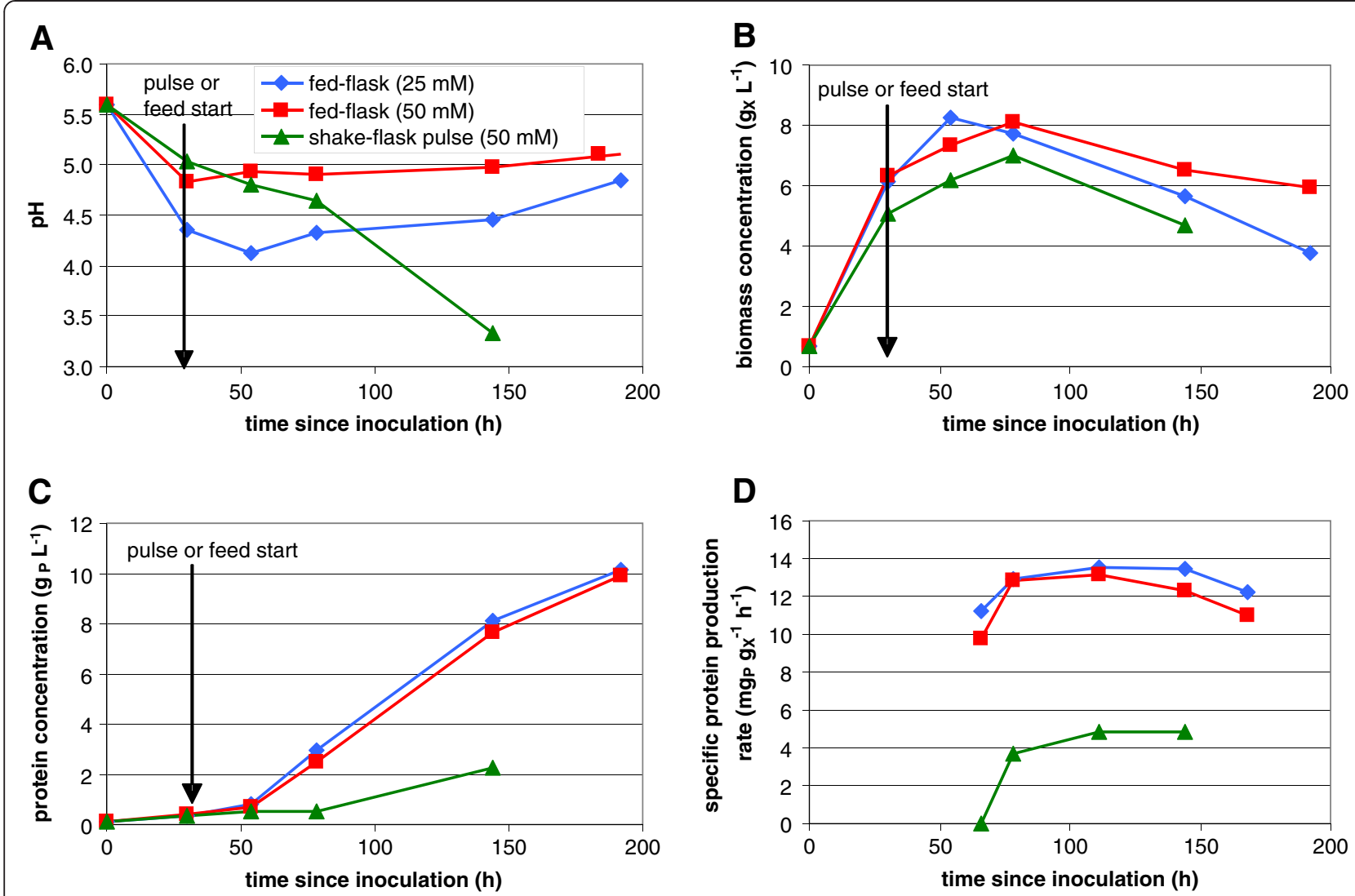

Figure 4 Validation of the miniaturized fed-flask protocol design. Reference strain T. reesei CL847 i 3 was cultivated in $50 \mathrm{~mL}$ shake-flask following shake flask pulse protocol (green triangles), or fed-flask protocol buffered with 25 (blue diamonds) or 50mM (red squares). pH (A), biomass concentration (B) and protein concentration (C) monitoring, and specific protein production rate calculation (moving average) (D).

to $\mathrm{pH}$ fall. Final lactose concentration was $14.8 \mathrm{~g} \mathrm{~L}^{-1}$, only $5.2 \mathrm{~g} \mathrm{~L}^{-1}$ lactose had been consumed before low $\mathrm{pH}$ inhibition occurred.

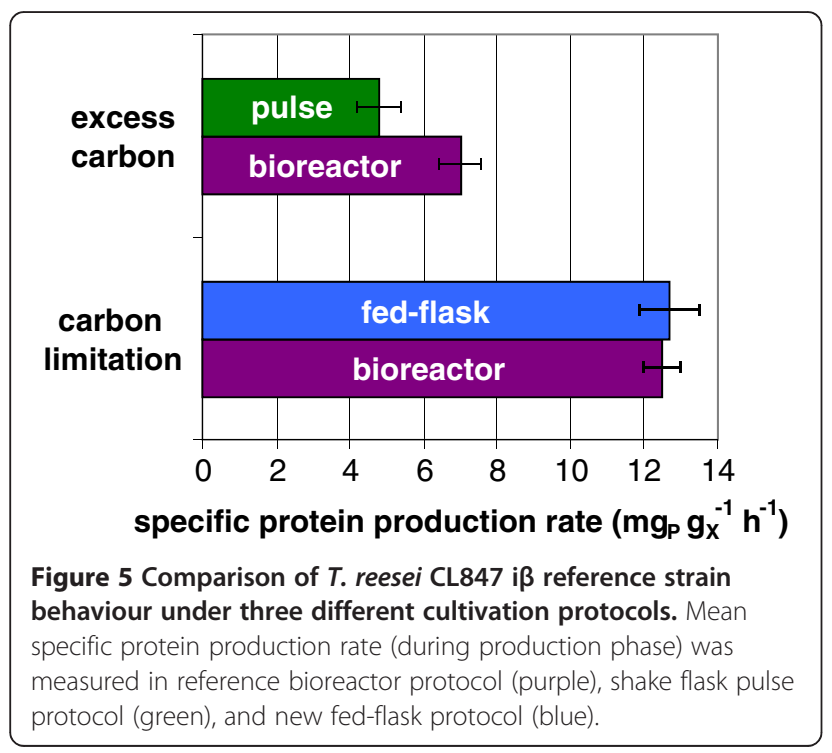

The specific protein production rate (Figure 4 D) was limited to $4.8 \mathrm{mg}_{\mathrm{P}} \mathrm{g}_{\mathrm{X}}^{-1} \mathrm{~h}^{-1}$ in the shake flask pulse protocol due to the excess of lactose. In contrast, in the new fed-flask protocol, it reached $12.7 \pm 0.8 \mathrm{mg}_{\mathrm{P}} \mathrm{g}_{\mathrm{X}}^{-1} \mathrm{~h}^{-1}$, owing to the carbon-limited feed which maintained residual sugar concentration close to zero (no residual sugar was detected by HPLC). Both values were consistent with those obtained in reference fed-batch bioreactor cultivation performed under comparable substrate feeding conditions (Figure 5). These results validated the new fed-flask protocol for the screening of strains with high hyperproducing capacity.

\section{Application to secondary screening}

To test this new protocol, a strain collection issued from a genetic engineering work was screened in order to rank the strains according to their protein production capacity in the operational conditions defined during the miniaturization.

During conidia purification and isolation steps, 25 clones were selected for stability, growth and general morphology on PDA plates. Then, a primary screening was achieved in classic shake flasks to check for 
transgene expression and protein production. For the secondary screening with the new fed-flask protocol, 4 clones $(\mathrm{A}, \mathrm{B}, \mathrm{C}, \mathrm{D})$ were selected for their good transgene expression and fair protein production levels (data not shown). These 4 clones were considered equivalent at the end of the primary screening. Clone $\mathrm{E}$ which lost the parental strain capacity to produce high levels of proteins was selected as a negative control. Parental strain $T$. reesei CL847 i $\beta$ was selected as a positive control. These 6 clones were tested by using the new fedflask protocol: feed was started after $50 \mathrm{~h}$ growth phase on $15 \mathrm{~g} \mathrm{~L}^{-1}$ glucose. The experiments were duplicated and gave similar results: Figure 6 presents the monitoring of the second experiment and average specific protein production rate.

During growth phase, the 6 clones showed differences in $\mathrm{pH}$ decrease (Figure 6 A). Since the buffer concentration was identical, these differences may reflect different growth rates, or different spore concentration at inoculation. During the fed-batch phase, clones $\mathrm{B}, \mathrm{C}$ and $\mathrm{D}$ showed a $\mathrm{pH}$ profile similar to the reference strain T. reesei CL847 i $\beta$, with a good $\mathrm{pH}$ stabilization, between 4 and 5 . On the other hand, clone A and negative control E showed a very quick rise of $\mathrm{pH}$, up to 8 , which completely inhibited biomass growth and protein production.

Biomass and protein profiles (Figure $6 \mathrm{~B}$ and $\mathrm{C}$ ) were similar for clones $\mathrm{C}$ and $\mathrm{D}$ and for reference strain $T$. reesei CL847 i $\beta$, with almost constant biomass concentration around $7 \mathrm{~g} \mathrm{~L}^{-1}$, and linear protein production up to around $7 \mathrm{~g} \mathrm{~L}^{-1}$ after $120 \mathrm{~h}$ feed. Clone B showed biomass accumulation up to $12 \mathrm{~g} \mathrm{~L}^{-1}$ and lower protein production, reaching $2.3 \mathrm{~g} \mathrm{~L}^{-1}$. Clone $\mathrm{A}$ and negative control $\mathrm{E}$ did not produce any protein.

The mean specific protein production rate (Figure $6 \mathrm{D}$ ) is the only reliable criterion to determine whether a strain is a hyperproducing one or not. Clones $\mathrm{A}$ and $\mathrm{B}$, like
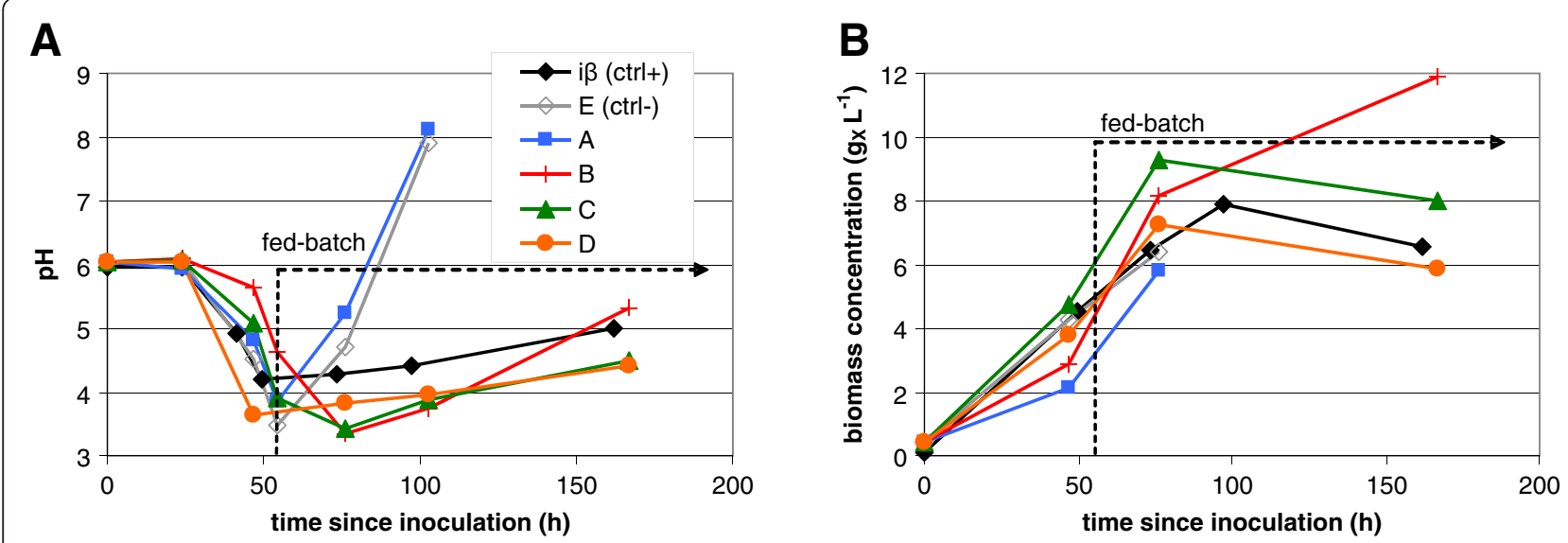

C
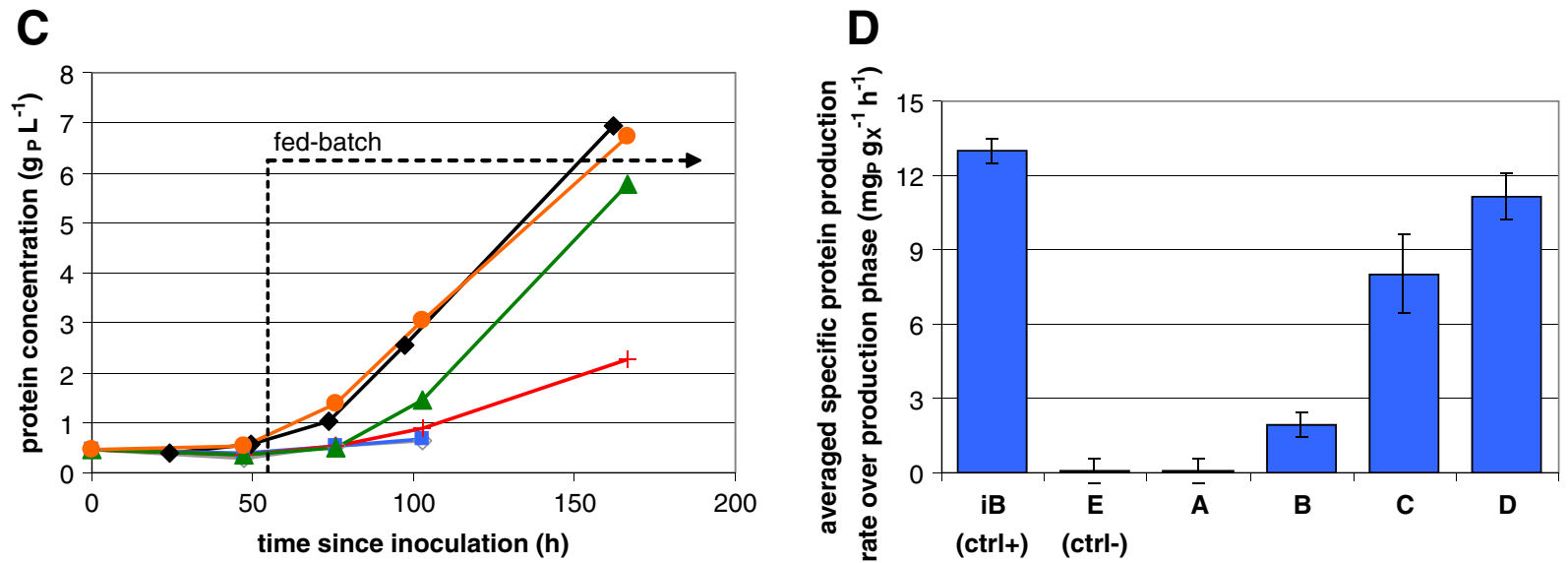

Figure 6 Application of the miniaturized fed-flask protocol to clone screening. Reference strain T. reesei CL847 i $\beta$ (black diamonds), and five recombinant strains: negative control $E$ (gray diamonds) and clones $A, B, C, D$ (respectively in blue squares, red cross, green triangles, orange circles), were cultivated in $50 \mathrm{~mL}$ shake flasks following fed-flask protocol: growth phase on $15 \mathrm{~g} \mathrm{~L}^{-1}$ glucose for $50 \mathrm{~h}$ then fed-batch with mixed lactose and ammonia feed (see Table 2). pH (A), biomass (B) and protein (C) monitoring, and specific protein production rate (D). Specific protein production rates were calculated over production phase (at constant biomass) and are mean and standard deviation of two independent replicates. 
negative control $\mathrm{E}$, lost the hyperproducing phenotype of the parental reference strain i $\beta$. Clone $D$ has almost the same specific protein production rate as the parental strain: it kept the hyperproducing phenotype. Clone C, which produced almost the same protein concentration, but with higher producing biomass concentration, has an intermediate phenotype, with a specific protein production rate $38 \%$ lower.

Using this new fed-flask protocol for a secondary screening step, 5 clones were ranked according to their protein production capacity, which was not possible during the first screening step with classic shake flasks protocol.

\section{Discussion}

\section{Compositional analysis of $T$. reesei secretomes}

Using three different secretomes produced by $T$. reesei in bioreactor fed-batch cultivations, the mean nitrogen mass content was measured at $12.7 \pm 0.5 \%$ instead of the usual $16 \%$. This result can be explained by the high glycosylation level of $T$. reesei cellulases [24]. For example, Hui et al. studied CBH2, EG1 and EG2 glycosylation patterns and determined that glycosylation accounted for 12 to $24 \%$ of their molecular mass [25]. Here, using mean theoretical cellulase composition and mean glycosylation composition, glycosylation was estimated to account for around $25 \%$ of the molecular mass of produced cellulases, which is consistent with Hui et al.

\section{Protocol design}

In order to design a small-scale protocol for secondary screening, the industrial fed-batch protocol had to be simplified as much as possible. In particular the complex $\mathrm{pH}$ control system, with $\mathrm{pH}$ probe and concentrated ammonia solution, had to be removed. Since the use of a lactose limited feed was compulsory to maintain maximal protein production, a new miniaturization strategy was proposed, based on the stoichiometric mix of carbon substrate and ammonia in the feed. Protein production stoichiometry in fed-batch cultivation was used to calculate the ammonia needed which was introduced with the lactose feed. This strategy was successful for $\mathrm{pH}$ stabilization and this result confirms that the stoichiometric equation used well describes protein production, especially because no organic acid or other ionic metabolite is produced. However, since this stoichiometry may slightly vary according to culture conditions, and since the growth phase is carried out without feed so without ammonia input, the culture medium needed to be buffered.

During fed-flask protocol validation, similar protein productions were observed in media buffered with 25 $\mathrm{mM}$ or $50 \mathrm{mM}$ phtalate. Although buffering is crucial in flasks experiments, a weaker buffer system was chosen for the screening experiments, with $25 \mathrm{mM}$ phtalate, since high buffer concentration may have an effect on cells behaviour [18]. Moreover, $\mathrm{pH}$ drop during growth phase is a good indicator of sugar consumption, which is the major criterion for deciding to start the feeding. During production phase, $\mathrm{pH}$ is mainly stabilized by the stoichiometric ammonia input from feed, so buffer concentration is less important. However, a $\mathrm{pH}$ drop below 3.5 , as observed in shake flask pulse protocol, may inactivate produced enzymes.

\section{Oxygen transfer}

Due to their low $\mathrm{K}_{\mathrm{L}}$ a values, oxygen transfer is often considered as the main issue in shake flasks, especially for high cell density experiments [12]. In preliminary experiments, slower growth was observed in $100 \mathrm{~mL}$ working volume compared to $50 \mathrm{~mL}$, due to oxygen transfer rate limitation (data not shown). Therefore a 50 $\mathrm{mL}$ working volume was chosen. During the fed-batch step, the volume increased but the oxygen demand was lower than in the growth phase since the carbon source supply was limited by the feed rate. So, oxygen was not a limiting nutriment during fed-batch, which is consistent with the fact that lactose residual concentration remained close to zero.

To validate this hypothesis, we calculated the minimal $\mathrm{K}_{\mathrm{L}} \mathrm{a}$ needed to allow sufficient oxygen transfer during production phase. Using measured protein production stoichiometry and set lactose feed rate in our experimental conditions (Table 2), the oxygen consumption rate was calculated to be $200 \mathrm{mg}_{\mathrm{O} 2} \mathrm{~L}^{-1} \mathrm{~h}^{-1}$. Then the minimum $K_{L}$ a value (for null dissolved oxygen concentration) was estimated at a value of $25 \mathrm{~h}^{-1}$. Every experimental device allowing $\mathrm{K}_{\mathrm{L}}$ a above this value will be sufficient for our experimental conditions. For shake flasks, this value is consistent with $\mathrm{K}_{\mathrm{L}}$ a measured by Wittman et al. [26]: around $80 \mathrm{~h}^{-1}$ in shake flasks with $50 \mathrm{~mL}$ water at $150 \mathrm{rpm}$.

Oxygen transfer in flasks is a critical issue when designing fed-batch mode which maintains substrate limitation. The simple calculation described above for the minimal $\mathrm{K}_{\mathrm{L}}$ a value needed can direct the choice of the experimental device.

\section{pH monitoring}

Clone $\mathrm{A}$ and negative control $\mathrm{E}$ did not produce any protein and showed a quick $\mathrm{pH}$ rise after lactose feed start. They might have lost the ability to metabolize lactose, which accumulated in the culture medium (up to $12 \mathrm{~g} \mathrm{~L} \mathrm{~L}^{-1}$ at $100 \mathrm{~h}$, whereas residual concentration remained null for clones $\mathrm{B}$ to $\mathrm{D})$. Then nitrogen from feed was not co-metabolized and ammonia also accumulated in the medium (up to $85 \mathrm{mM}$ at $100 \mathrm{~h}$, whereas it remained constant at around $40 \mathrm{mM}$ for clones $\mathrm{B}$ to D), 
leading to this quick $\mathrm{pH}$ rise. Clone $\mathrm{B}$ used lactose feed for growth instead of protein production, with similar mass yield on lactose. But the amount of nitrogen needed for growth is lower than the one used for protein production (Harima et Humphrey measured a nitrogen mass content of $6.7 \%$ for $T$. reesei QM9414 strain [27]). In our miniaturization strategy, ammonia input was based on nitrogen content in proteins, so clone B accumulated ammonia in culture medium (up to $50 \mathrm{mM}$ at $166 \mathrm{~h}$ ), which explains the quicker $\mathrm{pH}$ rise for clone $\mathrm{B}$ cultivation than for positive control CL847 i $\beta$ strain. Then a $\mathrm{pH}$ rise quicker than positive control may be a good indicator to eliminate clones with lower enzyme producing capacity.

\section{Fed-flask protocol advantages}

The comparison of the flasks protocols using reference strain T. reesei CL847 i $\beta$ (Figure 5) showed that protocols in flasks which do not handle the carbon limitation are not suitable to rank hyperproducing strains according to their specific protein production rate, whereas the fed-flask protocol did. It will be essential after genetic engineering works to quickly and reliably select strains which will have the best productivity at an industrial scale.

Moreover this new fed-flask protocol requires much less equipment than bioreactor cultivation: no bioreactor, only flasks and rotary shaker; no $\mathrm{pH}$ control system (neither $\mathrm{pH}$ probe nor base nor additional controlled pump); no dissolved oxygen control system (neither oxygen probe nor compressed air nor motor). In addition, the number of pumps for feeding can be reduced using the parallel feeding system developed by Weuster-Botz et al. [11]. Thereby it allows efficient secondary screening of collections of strains. We estimated that an operator who needed 2 weeks to carry out 4 bioreactor cultivations in parallel, can carry out 16 fed-flask cultivations per week, that is, a 8-fold increase.

\section{Miniaturization strategy}

The miniaturization strategy proposed in this study was developed to mimic an industrial process. It may be applied for the miniaturization of many other industrial biotechnological processes. Its main advantage is to allow $\mathrm{pH}$ stabilization in flasks when operated in carbon-limited fed-batch mode. Therefore this strategy is suitable for every fed-batch process, provided that $\mathrm{pH}$ variation can be related to the consumption of the substrate present in the feed. In this study, a stoichiometric approach was used to determine the relation between lactose and ammonia consumption, but an empirical approach can also be used for this determination. In the general case, even overflow metabolites as organic acids may be considered, as long as their production is stoichiometrically linked to substrate consumption.

Moreover, this miniaturized protocol can be used for other applications. Unlike strategies based on diffusional or enzymatic release, this strategy can be applied to complex feed compositions and to accurate feed rate profiles, provided that the pump system allows precise rate control. Therefore the resulting protocol can also be used to test the effect of the feed composition or the feed rate on the behaviour of a given strain.

\section{Conclusion}

A new strategy has been proposed for the design of screening protocols, which ensures a simpler and more accurate miniaturization of fed-batch operated bioprocess. Based on a stoichiometric study of the bioprocess, the feed composition may be designed to supply every nutriment and base or acid requirements in a single solution. Its main advantage is to enable a good $\mathrm{pH}$ stabilization without control system. Therefore strain behaviour is identical to $\mathrm{pH}$-regulated bioreactor cultivation so that the screening is carried out in industrial-like conditions. Moreover, less equipment is needed for the screening of strain collection or experimental conditions, since it does not require any $\mathrm{pH}$ probe or additional pump.

This strategy was applied to cellulase production by $T$. reesei, a key step for the biochemical conversion of lignocellulosic materials. The resulting protocol was validated using reference fed-batch production in bioreactor then applied to the secondary screening of several clones in bioreactor-like operational conditions. It succeeded in selecting an engineered hyper-producing strain with high industrial potential.

\section{Methods}

\section{Compositional analysis}

To determine the stoichiometry of protein production by $T$. reesei, compositional analysis of several supernatants was realized by SGS Multilab (Evry, France). To avoid concurrent measurement of remaining ions from culture medium, supernatants were first desalted using FPLC (Akta; GE Healthcare) equipped with Hitrap desalting column, then lyophilized.

\section{Culture media}

For bioreactor cultivations, the medium composition was: cornsteep solid $4 \mathrm{~g} \mathrm{~L}^{-1}$; $\mathrm{KOH} 1.66 \mathrm{~g} \mathrm{~L}^{-1} ; \mathrm{H}_{3} \mathrm{PO}_{4} 85 \% 2.5$ $\mathrm{mL} \mathrm{L}^{-1} ;\left(\mathrm{NH}_{4}\right)_{2} \mathrm{SO}_{4} 2.8 \mathrm{~g} \mathrm{~L}^{-1} ; \mathrm{MgSO}_{4}, 7 \mathrm{H}_{2} \mathrm{O} 0.6 \mathrm{~g} \mathrm{~L}^{-1}$; $\mathrm{CaCl}_{2}, 2 \mathrm{H}_{2} \mathrm{O} 0.6 \mathrm{~g} \mathrm{~L}^{-1} ; \mathrm{FeSO}_{4}-7 \mathrm{H}_{2} \mathrm{O} 60 \mathrm{mg} \mathrm{L}{ }^{-1} ; \mathrm{MnSO}_{4}$, $\mathrm{H}_{2} \mathrm{O} 12 \mathrm{mg} \mathrm{L}^{-1} ; \mathrm{ZnSO}_{4}, 7 \mathrm{H}_{2} \mathrm{O} 16 \mathrm{mg} \mathrm{L}^{-1} ; \mathrm{CoNO}_{3}, 6 \mathrm{H}_{2} \mathrm{O}$ $18 \mathrm{mg} \mathrm{L}^{-1} ; \mathrm{H}_{3} \mathrm{BO}_{3} 2 \mathrm{mg} \mathrm{L}^{-1}$. $\mathrm{pH}$ is adjusted to 4.8 with $\mathrm{NH}_{3} 20 \%$. 
For shake flasks, fed-flasks, and preculture cultivations, the media composition was: cornsteep solid $1.5 \mathrm{~g}$ $\mathrm{L}^{-1}$; dipotassium phtalate $6 \mathrm{~g} \mathrm{~L}^{-1}$ (case $25 \mathrm{mM}$ ) or $12 \mathrm{~g}$ $\mathrm{L}^{-1}$ (case $50 \mathrm{mM}$ ); $\mathrm{H}_{3} \mathrm{PO}_{4} 85 \% 0.8 \mathrm{~mL} \mathrm{~L}^{-1} ;\left(\mathrm{NH}_{4}\right)_{2} \mathrm{SO}_{4}$ $4.2 \mathrm{~g} \mathrm{~L}^{-1} ; \mathrm{MgSO}_{4}, 7 \mathrm{H}_{2} \mathrm{O} 0.3 \mathrm{~g} \mathrm{~L}^{-1} ; \mathrm{CaCl}_{2}, 2 \mathrm{H}_{2} \mathrm{O} 0.15 \mathrm{~g} \mathrm{~L}^{-1}$; $\mathrm{FeSO}_{4}-7 \mathrm{H}_{2} \mathrm{O} \quad 30 \mathrm{mg} \mathrm{L}^{-1} ; \mathrm{MnSO}_{4}, \mathrm{H}_{2} \mathrm{O} 6 \mathrm{mg} \mathrm{L} \mathrm{L}^{-1}$; $\mathrm{ZnSO}_{4}, 7 \mathrm{H}_{2} \mathrm{O} 8 \mathrm{mg} \mathrm{L}^{-1}$; $\mathrm{CoNO}_{3}, 6 \mathrm{H}_{2} \mathrm{O} 9 \mathrm{mg} \mathrm{L}^{-1} ; \mathrm{H}_{3} \mathrm{BO}_{3}$ $1 \mathrm{mg} \mathrm{L}^{-1}$. pH was adjusted to 6.0 with $\mathrm{NaOH} 30 \%$.

\section{Strains}

T. reesei CL847 i $\beta$ was obtained by genetic engineering of the hyperproducer CL847 strain, both from Cayla Company, Toulouse France [28,29]. Clones used to test the new protocol were obtained by genetic engineering from $T$. reesei CL847 i 3 strain. All strains were maintained on PDA plates.

\section{Bioreactor cultivations}

For a standard fed-batch production based on the industrial protocol [30], cultivation was carried out in Dasgip fedbatch-pro bioreactors with an initial working volume of $750 \mathrm{~mL}$. Growth phase in batch was performed on 20 $\mathrm{g} \mathrm{L}^{-1}$ glucose at $\mathrm{pH} 4.8$ and $27{ }^{\circ} \mathrm{C}$ for $30 \mathrm{~h}$. Then fedbatch was performed at $\mathrm{pH} 4.0$ and $25{ }^{\circ} \mathrm{C}$ with $250 \mathrm{~g} \mathrm{~L}^{-1}$ lactose solution feed at $2 \mathrm{~mL} \mathrm{~h}^{-1}$. $\mathrm{pH}$ was automatically adjusted with $5.5 \mathrm{~N} \mathrm{NH}_{3}$ solution. Aeration rate was fixed at $30 \mathrm{sL} \mathrm{h}^{-1}$ and agitation was regulated to maintain $40 \%$ dissolved oxygen.

\section{Flasks cultivations}

$500 \mathrm{~mL}$ Schott flasks with $50 \mathrm{~mL}$ working volume were incubated at $30{ }^{\circ} \mathrm{C}$ and $150 \mathrm{rpm}$ in an Infors rotary shaker.

For shake flask pulse protocol, the culture medium was buffered with $50 \mathrm{mM}$ dipotassium phtalate. Growth phase was performed on $15 \mathrm{~g} \mathrm{~L}^{-1}$ glucose for $33 \mathrm{~h}$. Then protein production was induced with a $20 \mathrm{~g} \mathrm{~L}^{-1}$ lactose pulse.

The new fed-flask protocol was designed by stoichiometric miniaturization of the bioreactor protocol (see text, Table 2, and Figure 3), for an initial working volume of $50 \mathrm{~mL}$ and a biomass concentration around $8 \mathrm{~g} \mathrm{~L}^{-1}$. Growth phase was performed on $15 \mathrm{~g} \mathrm{~L}^{-1}$ glucose for $50 \mathrm{~h}$ (until glucose concentration below $5 \mathrm{~g} \mathrm{~L}^{-1}$ ) then flasks were fed at $0.3 \mathrm{~mL} \mathrm{~h}^{-1}$ with a mixed solution containing: lactose $50 \mathrm{~g} \mathrm{~L}^{-1}$; $\mathrm{NH}_{3} 20 \%(11 \mathrm{~N}) 15 \mathrm{~mL} \mathrm{~L}^{-1}$; $\left(\mathrm{NH}_{4}\right)_{2} \mathrm{SO}_{4} 0.8 \mathrm{~g} \mathrm{~L}^{-1}$. This composition was calculated from the stoichiometry of protein production to meet carbon, nitrogen and sulfur requirements, and to stabilize $\mathrm{pH}$.

\section{Analysis}

Culture medium was filtrated using Whatman GF/C filters. For biomass concentration determination, biomass cake was washed with distilled water then dried at 105 ${ }^{\circ} \mathrm{C}$ until constant weight . For protein concentration determination, supernatants were diluted with distilled water then protein concentration was measured against BSA standard (0-1.5 $\mathrm{g} \mathrm{L}^{-1}$ range with second-order regression) by Lowry method [31] using DC Protein Assay (Biorad). Sugars concentration was measured by HPLC: separation was carried out using Varian Metacarb $87 \mathrm{P}$ column with mobile phase milliQ water at 0.4 $\mathrm{mL} \min ^{-1}, 80{ }^{\circ} \mathrm{C}$ and pressure around 32 bar; detection was carried out with Waters 2414 refractive index detector. Ammonium concentration was measured by HPLC: separation was carried out using Dionex IonPac CS12A column with mobile phase methanesulfonic acid

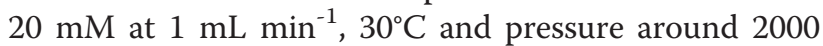
psi; detection was carried out with Dionex CD conductivity detector at $35^{\circ} \mathrm{C}$.

\section{Competing interests}

IFP Energies nouvelles has filed a patent application on this methodology.

\section{Acknowledgements}

This study was part of Projet Futurol, a project supported by OSEO Innovation. Antoine Margeot and Hugues Mathis (IFP Energies nouvelles) are acknowledged for the construction of mutant strains used in this work.

\section{Author details}

${ }^{1}$ IFP Energies nouvelles, 1 et 4 avenue de Bois-Préau, 92852 Rueil-Malmaison, France. ${ }^{2}$ Clermont Université, Université Blaise Pascal, Institut Pascal, Polytech Clermont-Ferrand, 24 av. des Landais, BP 20206, 63174 Aubière cedex, France.

\section{Authors' contributions}

EJ and FBC designed the study. EJ carried out the experiments and drafted the manuscript. CL and LP are academic supervisers of EJ. All authors revised, read and approved the final manuscript.

Received: 22 March 2012 Accepted: 30 May 2012

Published: 30 May 2012

\section{References}

1. Scheidle M, Jeude M, Dittrich B, Denter S, Kensy F, Suckow M, Klee D, Buchs J: High-throughput screening of Hansenula polymorpha clones in the batch compared with the controlled-release fed-batch mode on a small scale. FEMS Yeast Res 2010, 10:83-92.

2. Blomberg A: Measuring growth rate in high-throughput growth phenotyping. Curr Opin Biotechnol 2011, 22:94-102.

3. Funke M, Buchenauer A, Schnakenberg U, Mokwa W, Diederichs S, Mertens A, Muller C, Kensy F, Buchs J: Microfluidic biolector-microfluidic bioprocess control in microtiter plates. Biotechnol Bioeng 2010, 107:497-505.

4. Betts J, Baganz F: Miniature bioreactors: current practices and future opportunities. Microb Cell Fact 2006, 5:21.

5. Weuster-Botz D, Puskeiler R, Kusterer A, Kaufmann K, John GT, Arnold M Methods and milliliter scale devices for high-throughput bioprocess design. Bioprocess Biosyst Eng 2005, 28:109-119.

6. Schapper D, Alam MNHZ, Szita N, Lantz AE, Gernaey KV: Application of microbioreactors in fermentation process development: a review. Anal Bioanal Chem 2009, 395:679-695.

7. Jeude M, Dittrich B, Niederschulte H, Anderlei T, Knocke C, Klee D, Buchs J: Fed-batch mode in shake flasks by slow-release technique. Biotechnol Bioeng 2006, 95:433-445.

8. Panula-Perala J, Siurkus J, Vasala A, Wilmanowski R, Casteleijn MG, Neubauer $P$ : Enzyme controlled glucose auto-delivery for high cell density cultivations in microplates and shake flasks. Microb Cell Fact 2008, 7:31. 
9. Hemmerich J, Wenk P, Lutkepohl T, Kensy F: Fed-batch cultivation in baffled shake flasks fed-batch mode. Genet Eng Biotechnol News 2011, 31:52-54.

10. Scheidle M, Dittrich B, Klinger J, Ikeda H, Klee D, Buchs J: Controlling pH in shake flasks using polymer-based controlled-release discs with pre-determined release kinetics. BMC Biotechnol 2011, 11:25.

11. Weuster-Botz D, Altenbach-Rehm J, Arnold M: Parallel substrate feeding and pH-control in shaking-flasks. Biochem Eng J 2001, 7:163-170.

12. Bareither R, Pollard D: A review of advanced small-scale parallel bioreactor technology for accelerated process development: current state and future need. Biotechnol Prog 2011, 27:2-14.

13. Ballerini D, Desmarquest JP, Pourquie J, Nativel F, Rebeller M: Ethanol production from lignocellulosics - large-scale experimentation and economics. Bioresour Technol 1994, 50:17-23.

14. Margeot A, Hahn-Hagerdal B, Edlund M, Slade R, Monot F: New improvements for lignocellulosic ethanol. Curr Opin Biotechnol 2009, 20:372-380

15. Pourquie J, Warzywoda M, Chevron F, Thery D, Lonchamp D, Vandecasteele JP: Scale up of cellulase production and utilization. In FEMS Symposium n43: Biochemistry and Genetics of Cellulose Degradation. Edited by Aubert J-P, Beguin P, Millet J. London: Academic; 1988:71-86.

16. Dashtaban M, Buchkowski R, Qin W: Effect of different carbon sources on cellulase production by Hypocrea jecorina (Trichoderma reesei) strains. Int J Biochem Mol Biol 2011, 2:274-286.

17. Tolan J, Foody B: Cellulase from Submerged Fermentation. In Recent Progress in Bioconversion of Lignocellulosics. 65th edition. Edited by Tsao G, Brainard A, Bungay $H$, Cao N, Cen P, Chen Z, Du J, Foody B, Gong C, Hall P Ho N, Irwin D, lyer P, Jeffries T, Ladisch C, Ladisch M, Lee Y, Mosier N, Mühlemann H, Sedlak M, Shi N, Tsao G, Tolan J, Torget R, Wilson D, Xia L. Berlin/Heidelberg: Springer; 1999:41-67.

18. Ferreira SMP, Duarte AP, Queiroz JA, Domingues FC: Influence of buffer systems on Trichoderma reesei Rut C-30 morphology and cellulase production. Electronic Journal of Biotechnology 2009, 12(3):6.

19. Juhasz T, Szengyel Z, Szijarto N, Reczey K: Effect of pH on cellulase production of Trichoderma reesei RUT C30. Appl Biochem Biotechnol 2004 113:201-211.

20. Herpoel-Gimbert I, Margeot A, Dolla A, Jan G, Molle D, Lignon S, Mathis H, Sigoillot JC, Monot F, Asther M: Comparative secretome analyses of two Trichoderma reesei RUT-C30 and CL847 hypersecretory strains. Biotechnol Biofuels 2008, 1:18.

21. Cianchetta S, Galletti S, Burzi PL, Cerato C: A novel microplate-based screening strategy to assess the cellulolytic potential of trichoderma strains. Biotechnol Bioeng 2010, 107:461-468.

22. Morikawa Y, Ohashi T, Mantani O, Okada H: Cellulase induction by lactose in Trichoderma reesei PC-3-7. Appl Microbiol Biotechnol 1995, 44:106-111.

23. Martinez D, Berka RM, Henrissat B, Saloheimo M, Arvas M, Baker SE, Chapman J, Chertkov O, Coutinho PM, Cullen D, Danchin EGJ, Grigoriev IV, Harris P, Jackson M, Kubicek CP, Han CS, Ho I, Larrondo LF, de Leon AL, Magnuson JK, Merino S, Misra M, Nelson B, Putnam N, Robbertse B, Salamov AA, Schmoll M, Terry A, Thayer N, Westerholm-Parvinen A, et al: Genome sequencing and analysis of the biomass-degrading fungus Trichoderma reesei (syn. Hypocrea jecorina). Nat Biotechnol 2008, 26:553-560.

24. Kruszewska JS, Perlinska-Lenart U, Gorka-Niec W, Orlowski J, Zembek P, Palamarczyk G: Alterations in protein secretion caused by metabolic engineering of glycosylation pathways in fungi. Acta Biochim Pol 2008, 55:447-456

25. Hui JPM, White TC, Thibault P: Identification of glycan structure and glycosylation sites in cellobiohydrolase II and endoglucanases I and II from Trichoderma reesei. Glycobiology 2002, 12:837-849.

26. Wittmann C, Kim HM, John G, Heinzle E: Characterization and application of an optical sensor for quantification of dissolved 0-2 in shake-flasks. Biotechnol Lett 2003, 25:377-380.

27. Harima T, Humphrey AE: Estimation of Trichoderma QM 9414 biomass and growth-rate by indirect means. Biotechnol Bioeng 1980, 22:821-831.

28. Durand $\mathrm{H}$, Clanet M, Tiraby $\mathrm{G}$ : Genetic-improvement of trichodermareesei for large-scale cellulase production. Enzyme Microb Technol 1988, 10:341-346.

29. Durand H, Baron M, Calmels T, Tiraby G: Classical and molecular genetics applied to Trichoderma reesei for the selection of improved cellulolytic industrial strains. In FEMS Symposium n 43: Biochemistry and Genetics of
Cellulose Degradation. Edited by Aubert J-P, Beguin P, Millet J. London: Academic; 1988:135-151.

30. Warzywoda M, Ferre V, Pourquie J: Process for producing cellulolytic enzymes. Institut Français du Pétrole R-MF 1988, 9:8. 675595(US4762788). 28-11-1984.

31. Lowry OH, Rosebrough NJ, Farr AL, Randall RJ: Protein measurement with the Folin phenol reagent. J Biol Chem 1951, 193:265-275.

doi:10.1186/1475-2859-11-70

Cite this article as: Jourdier et al: A new stoichiometric miniaturization strategy for screening of industrial microbial strains: application to cellulase hyper-producing Trichoderma reesei strains. Microbial Cell Factories 2012 11:70.

\section{Submit your next manuscript to BioMed Central and take full advantage of:}

- Convenient online submission

- Thorough peer review

- No space constraints or color figure charges

- Immediate publication on acceptance

- Inclusion in PubMed, CAS, Scopus and Google Scholar

- Research which is freely available for redistribution 